\title{
Addition of a $\beta$ 1-Blocker to Milrinone Treatment Improves Cardiac Function in Patients with Acute Heart Failure and Rapid Atrial Fibrillation
}

\author{
Shigeki Kobayashia ${ }^{a}$ Takeki Myoren ${ }^{a}$ Toshiro Kajii ${ }^{a}$ Michiaki Kohno ${ }^{a}$ \\ Takuma Nanno $^{a}$ Hironori Ishiguchi ${ }^{a}$ Shigehiko Nishimura ${ }^{a}$ \\ Masakazu Fukuda ${ }^{a}$ Akihiro Hino ${ }^{a}$ Tatsuhiro Fujimura ${ }^{a}$ Makoto Ono ${ }^{a}$ \\ Hitoshi Uchinoumi $^{a}$ Hiroki Tateishi ${ }^{a}$ Mamoru Mochizukia ${ }^{\text {Tetsuro Oda }}{ }^{a}$ \\ Shinichi Okuda ${ }^{a}$ Yasuhiro Yoshiga $^{a}$ Reo Kawano $^{b}$ Masafumi Yano $^{a}$ \\ ${ }^{a}$ Division of Cardiology, Department of Medicine and Clinical Science, Yamaguchi University Graduate School of \\ Medicine, Ube, Japan; ${ }^{b}$ Center for Integrated Medical Research, Hiroshima University Hospital, Hiroshima, Japan
}

\section{Keywords}

Acute decompensated heart failure $\cdot \beta$-Blocker $\cdot$ Milrinone .

Atrial fibrillation · Tachycardia

\begin{abstract}
Background: Tachycardia worsens cardiac performance in acute decompensated heart failure (ADHF). We investigated whether heart rate (HR) optimization by landiolol, an ultrashort-acting $\beta 1$-selective blocker, in combination with milrinone improved cardiac function in patients with ADHF and rapid atrial fibrillation (AF). Methods and Results: We enrolled 9 ADHF patients (New York Heart Association classification IV; HR, $138 \pm 18$ bpm; left ventricular [LV] ejection fraction, $28 \pm 8 \%$; cardiac index $[\mathrm{Cl}], 2.1 \pm 0.3 \mathrm{~L} / \mathrm{min}^{-1} / \mathrm{m}^{-2}$; pulmonary capillary wedge pressure [PCWP], $24 \pm 3 \mathrm{~mm} \mathrm{Hg}$ ), whose HRs could not be reduced using standard treatments, including diuretics, vasodilators, and milrinone. Landiolol (1.5-6.0 $\mu \mathrm{g} / \mathrm{kg}^{-1} / \mathrm{min}^{-1}$, intravenous) was added to milrinone treatment to study its effect on hemodynamics. The addition of landiolol $\left(1.5 \mu \mathrm{g} / \mathrm{kg}^{-1} / \mathrm{min}^{-1}\right)$ significantly reduced $\mathrm{HR}$ by $11 \%$ without changing systolic blood pressure (BP) and resulted in a significant decrease in PCWP and a significant in-
\end{abstract}

\section{KARGER}

(c) 2019 S. Karger AG, Basel

E-Mail karger@karger.com

www.karger.com/crd crease in stroke volume index (SVI), suggesting that HR reduction restores incomplete $L V$ relaxation. Administration of more than $3.0 \mu \mathrm{g} / \mathrm{kg}^{-1} / \mathrm{min}^{-1}$ of landiolol decreased $\mathrm{BP}, \mathrm{Cl}$, and SVI. Conclusion: The addition of landiolol at doses of $<3.0 \mu \mathrm{g} / \mathrm{kg} / \mathrm{min}$ to milrinone improved cardiac function in decompensated chronic heart failure with rapid atrial fibrillation by selectively reducing $\mathrm{HR}$.

(c) 2019 S. Karger AG, Basel

\section{Introduction}

Tachycardia worsens cardiac performance in patients with acute decompensated heart failure (ADHF) and severe left ventricular (LV) dysfunction by decreasing diastolic filling and increasing myocardial oxygen demand [1]. Furthermore, tachycardia itself results in abnormalities in intracellular $\mathrm{Ca}^{2+}$ handling [2-4], LV dysfunction, and LV remodeling [5].

Landiolol (ONOACT ${ }^{\circledR}$; Ono Pharmaceutical, Osaka, Japan) is an ultra-short-acting (elimination half-life 4 $\mathrm{min})$ intravenous $\beta 1$-selective $(\beta 1 / \beta 2=255)$ adrenergic receptor blocker that is similar to esmolol [6-8]. How- 
ever, the important difference between the drugs is that landiolol has a greater chronotropic effect and a lesser inotropic effect than esmolol [6]. If a $\beta 1$-blocker can lower heart rate (HR) without suppressing cardiac function, the addition of a $\beta 1$-blocker would be beneficial for the treatment of ADHF with severe tachycardia. We previously reported that low-dose landiolol $(1.5 \mu \mathrm{g} /$ $\mathrm{kg}^{-1} / \mathrm{min}^{-1}$ ) in combination with milrinone safely decreased the HR in patients with severe ADHF and sinus tachycardia, thereby improving cardiac function, whereas high-dose landiolol (more than $3.0 \mu \mathrm{g} / \mathrm{kg}^{-1} / \mathrm{min}^{-1}$ ) suppressed cardiac function [7]. In addition, we reported that $1.5 \mu \mathrm{g} / \mathrm{kg}^{-1} / \mathrm{min}^{-1}$ of landiolol significantly decreased HR without lowering blood pressure (BP) in patients with rapid atrial fibrillation (AF) and heart failure (HF) [8]. These data suggested that HR control by lowdose landiolol is a new strategy for ADHF with tachycardia that is resistant to conventional HF treatments. We assessed whether HR optimization using landiolol in combination with milrinone improved LV function due to a rapid ventricular response to AF in ADHF patients.

\section{Methods}

We prospectively enrolled consecutive patients between March 2014 and December 2017. Patients were included if they were diagnosed with ADHF (New York Heart Association [NYHA] classification IV, depressed LV function [ejection fraction $\leq 0.35$ ], HR $\geq 120$ beats per minute [bpm], AF, and the absence of specific devices [intra-aortic balloon pump or percutaneous cardiopulmonary support system]) upon admission. Tachycardia (HR $\geq 120$ bpm) must have been continuous for more than $4 \mathrm{~h}$ after standard treatment with diuretics, vasodilators, and milrinone. The enrolled patients underwent electrocardiographic and invasive hemodynamic monitoring with a Swan-Ganz catheter and an arterial catheter. Their baseline HR, BP, electrocardiographic findings, and cardiac hemodynamic variables were measured. The initial treatment included diuretics and vasodilators, followed by milrinone $\left(0.25-0.5 \mu \mathrm{g} / \mathrm{kg}^{-1} / \mathrm{min}^{-1}\right)$. When hemodynamic parameters plateaued at $\geq 4 \mathrm{~h}$ after the initial treatment, landiolol $(1.5-6.0 \mu \mathrm{g}$ / $\mathrm{kg}^{-1} / \mathrm{min}^{-1}$ ) was administered to study its effect on hemodynamic variables, and landiolol was dosed up in a step-wise manner every hour. The patients' hemodynamics were measured by a SwanGanz catheter. When there was a $>20 \%$ decrease in systolic BP, when the systolic BP was $<80 \mathrm{~mm} \mathrm{Hg}$, or when cardiac output was decreased twice in succession, further landiolol dosage increases were halted. The primary endpoint of this study was the change in hemodynamic variables (HR, BP, cardiac index [CI], stroke volume index [SVI], and pulmonary capillary wedge pressure [PCWP]) after landiolol administration. All echocardiography data were measured by an experienced echocardiographer who was blinded to the patients in the study. Landiolol was used in an off-label manner.
Statistical Analyses

Continuous variables are expressed as the mean \pm standard deviation. The hemodynamic indices between 1.5 and $6.0 \mu \mathrm{g} / \mathrm{kg}^{-1} /$ $\min ^{-1}$ of landiolol were compared with the index at $0 \mu \mathrm{g} / \mathrm{kg}^{-1}$ / $\min ^{-1}$ using Dunnett's multiple comparison test. The Wilcoxon signed-rank test was used to compare hemodynamic changes between 0 and $1.5 \mu \mathrm{g} / \mathrm{kg}^{-1} / \mathrm{min}^{-1}$ of landiolol. All analyses were performed using SAS (University Edition 3.6, SAS Institute Inc., Cary, NC, USA.). $p$ values $<0.05$ were considered statistically significant.

\section{Results}

\section{Patient Characteristics}

A total of 20 patients with ADHF (NYHA IV, clinical profile of "wet and cold," and rapid AF [HR $\geq 120 \mathrm{bpm}]$ ) who were admitted to Yamaguchi University Hospital were initially screened. Eleven out of these 20 patients fulfilled the key requirements of low LV ejection fraction (LVEF; $\leq 35 \%$ ) and underwent Swan-Ganz catheter monitoring. Diuretics and/or vasodilators were initially administered to the 11 patients. In 2 of those patients, the HR gradually decreased to less than $120 \mathrm{bpm}$ over $4 \mathrm{~h}$. Therefore, these 2 patients were excluded from the analysis. In the remaining 9 patients, when the hemodynamic parameters plateaued at $\geq 4 \mathrm{~h}$ after treatment that included diuretics and/or vasodilators and milrinone, landiolol $\left(1.5-6.0 \mu \mathrm{g} / \mathrm{kg}^{-1} / \mathrm{min}^{-1}\right)$ was administered to study its effect on hemodynamic variables.

The baseline characteristics before the intravenous administration of diuretics, vasodilators, and milrinone of the 9 patients are shown in Table 1. Five patients were diagnosed with nonischemic dilated cardiomyopathy $(\mathrm{CM})$ and 4 were diagnosed with ischemic CM. The clinical severity of HF in all patients was NYHA IV and "wet and cold" according to the Nohria-Stevenson classification. Seven patients had chronic AF, while 2 had paroxysmal AF. Echocardiography data showed that the mean LV end-diastolic dimension and mean LVEF were $56 \mathrm{~mm}$ and $28 \%$, respectively. Hemodynamic data revealed that the mean HR was $138.0 \mathrm{bpm}$, mean CI was $2.1 \mathrm{~L} /$ $\mathrm{min}^{-1} / \mathrm{m}^{-2}$, mean PCWP was $23.5 \mathrm{~mm} \mathrm{Hg}$, and mean SVI was $15.0 \mathrm{~mL} / \mathrm{m}^{2}$. The oral medications, including ACE inhibitors, $\beta$-blockers, diuretics, and amiodarone, taken before admission are shown in Table 1.

Intravenous Administration of Diuretics,

Vasodilators, and Milrinone prior to Landiolol

Titration for the Treatment of ADHF

Table 2 shows the doses of diuretics, vasodilators, and milrinone used and the hemodynamic change prior to the 
Table 1. Baseline characteristics of patients with ADHF and rapid AF

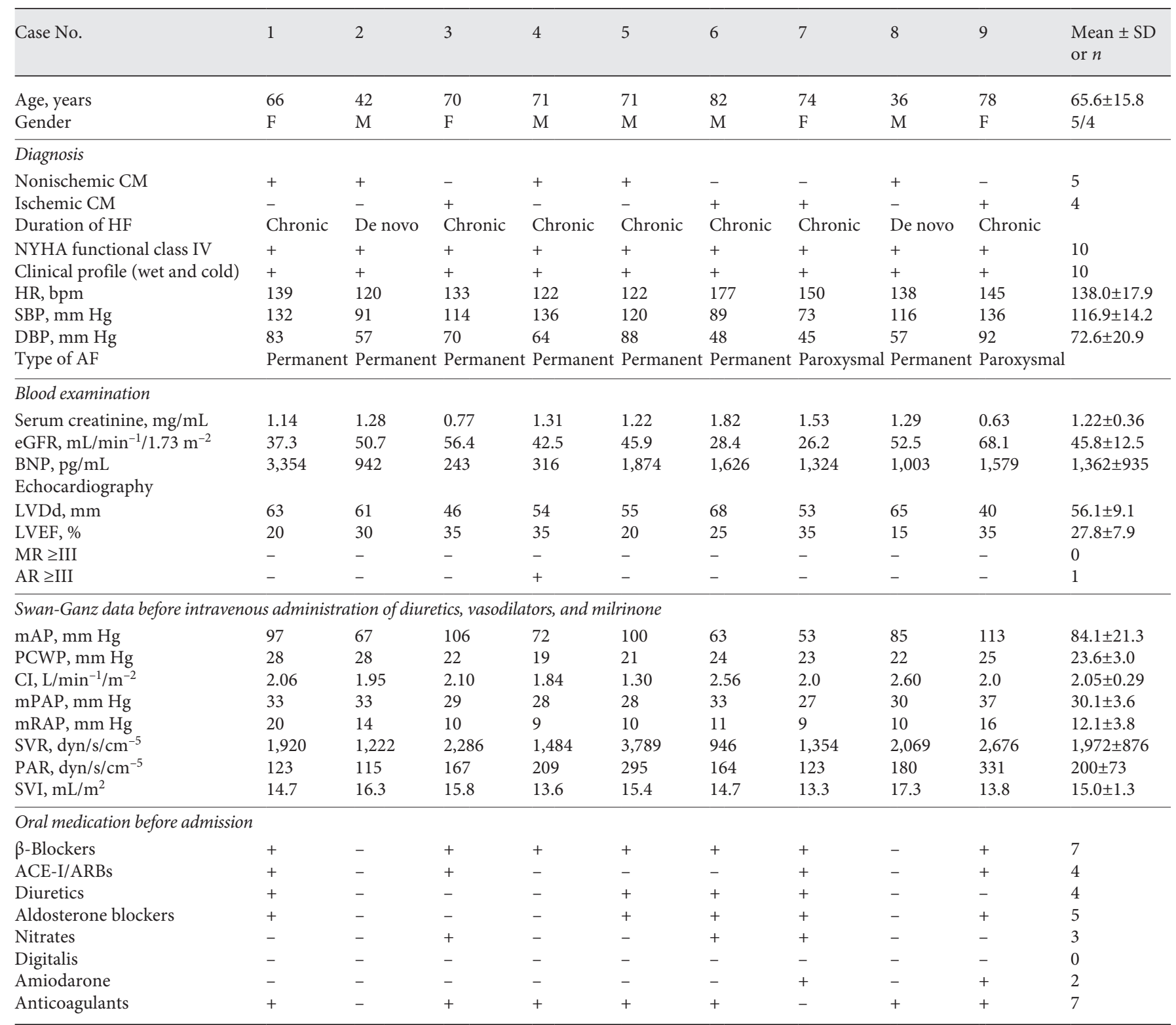

CM, cardiomyopathy; NYHA, New York Heart Association; HR, heart rate; SBP, systolic blood pressure; DSB, diastolic blood pressure; AF, atrial fibrillation; eGFR, estimated glomerular filtration rate; BNP, B-type natriuretic peptide; LVDd, end-diastolic left ventricular diameter; LVEF, left ventricular ejection fraction; $\mathrm{MR}$, mitral regurgitation; $\mathrm{AR}$, aortic regurgitation; $\mathrm{mAP}$, mean atrial pressure; PCWP, pulmonary capillary wedge pressure; $\mathrm{CI}$, cardiac index; $\mathrm{mPAP}$, mean pulmonary arterial pressure; $\mathrm{mRAP}$, mean right atrial pressure; SVR, systemic vascular resistance; PAR, pulmonary arterial resistance; SVI, stroke volume index.

administration of landiolol. As shown in Table 2 and Figure 1a, PCWP and right atrial pressure (RAP) significantly decreased and CI increased after the intravenous administration of these drugs as compared with those at baseline (change of PCWP $-5.4 \pm 4.2 \mathrm{~mm} \mathrm{Hg}$; change of RAP -4.4 $\pm 5.0 \mathrm{~mm} \mathrm{Hg}, p<0.05$, respectively), whereas HR did not decrease (change of $\mathrm{HR}+1.7 \pm 5.8 \mathrm{bpm}, p=\mathrm{ns}$ ).

$\beta$-Blocker and Milrinone in Acute Heart Failure

\section{Dose-Dependent Effect of Landiolol on Patient \\ Hemodynamics}

When compared with milrinone monotherapy with vasodilators and diuretics (at $0 \mu \mathrm{g} / \mathrm{kg}^{-1} / \mathrm{min}^{-1}$ of landiolol), HR significantly decreased with landiolol treatment in a dose-dependent manner, and infusing landiolol did not decrease BPs at 1.5 and $3.0 \mu \mathrm{g} / \mathrm{kg}^{-1} / \mathrm{min}^{-1}$ (Fig. 1a). 
Table 2. Response to the initial intravenous treatment of ADHF prior to the addition of landiolol

\begin{tabular}{|c|c|c|c|c|c|c|c|c|c|c|}
\hline Case No. & 1 & 2 & 3 & 4 & 5 & 6 & 7 & 8 & 9 & Mean \pm SD or $n$ \\
\hline $\begin{array}{l}\text { Furosemide, daily dosage, mg } \\
\text { Vasodilators }\end{array}$ & 60 & 60 & 40 & 30 & 20 & 50 & 100 & 60 & 80 & $55.6 \pm 24.6$ \\
\hline Nitroprusside, $\mu \mathrm{g} / \mathrm{kg}^{-1} / \mathrm{min}^{-1}$ & 0.6 & - & - & - & 0.9 & 0.6 & - & - & - & 4 \\
\hline Nitroglycerin, $\mu \mathrm{g} / \mathrm{kg}^{-1} / \mathrm{min}^{-1}$ & - & - & - & 0.3 & - & - & - & - & - & 1 \\
\hline Carperitide, $\mu \mathrm{g} / \mathrm{kg}^{-1} / \mathrm{min}^{-1}$ & - & - & 0.025 & - & & - & - & 0.025 & 0.025 & 3 \\
\hline Milrinone, $\mu \mathrm{g} / \mathrm{kg}^{-1} / \mathrm{min}^{-1}$ & 0.2 & 0.25 & 0.2 & 0.25 & 0.45 & 0.15 & 0.36 & 0.15 & 0.25 & $0.25 \pm .0 .10$ \\
\hline Change of RAP from baseline to prior to landiolol administration, $\mathrm{mm} \mathrm{Hg}$ & -14 & -7 & 0 & -8 & -1 & 0 & 0 & -2 & -8 & $-4.4 \pm 5.0$ \\
\hline Change of PCWP from baseline to prior to landiolol administration, $\mathrm{mm} \mathrm{Hg}$ & -14 & -8 & -5 & -5 & -3 & +1 & -3 & -4 & -8 & $-5.4 \pm 4.2$ \\
\hline Change of $\mathrm{CI}$ from baseline to prior to landiolol administration, $\mathrm{L} / \mathrm{min} / \mathrm{m}^{2}$ & +0.86 & +0.36 & +0.15 & -0.34 & +0.48 & +0.48 & 0.00 & +0.5 & +0.52 & $+0.33 \pm 0.35$ \\
\hline Change of HR from baseline to prior to landiolol administration, bpm & +1 & 0 & -7 & +13 & +8 & 0 & 0 & +2 & -2 & $+1.7 \pm 5.8$ \\
\hline
\end{tabular}

RAP, right atrial pressure; PCWP, pulmonary capillary wedge pressure; CI, cardiac index; HR, heart rate.

CI, SVI, and $\mathrm{O}_{2}$ saturation of mixed venous blood peaked at $1.5,3.0$, and $1.5 \mu \mathrm{g} / \mathrm{kg}^{-1} / \mathrm{min}^{-1}$, respectively (Fig. 1a). Infusing more than $3.0 \mu \mathrm{g} / \mathrm{kg}^{-1} / \mathrm{min}^{-1}$ of landiolol decreased SVI, indicating the negative inotropism of landiolol. As summarized in Figure $1 \mathrm{~b}$, a dose of $1.5 \mu \mathrm{g} / \mathrm{kg}^{-1}$ / $\mathrm{min}^{-1}$ of landiolol significantly decreased HR $(140 \pm 17$ to $125 \pm 16 \mathrm{bpm})$, which led to a decrease in PCWP $(18 \pm 3$ to $15 \pm 3 \mathrm{~mm} \mathrm{Hg})$, increases in CI $(2.37 \pm 0.31$ to $2.61 \pm$ $\left.0.44 \mathrm{~L} / \mathrm{min} / \mathrm{m}^{2}\right)$ and SVI $\left(17 \pm 3\right.$ to $21 \pm 4 \mathrm{~mL} /$ beat $\left./ \mathrm{m}^{2}\right)$, and oxygen saturation of mixed venous blood (62 \pm 7 to $68 \pm 7 \%$ ) without changing BPs, mean RAP, and systemic vascular resistance.

\section{Discussion}

The most important result was that the combination therapy of landiolol and milrinone improved cardiac function to a greater degree than milrinone monotherapy, including diuretics, vasodilators, and milrinone, in ADHF patients with refractory rapid AF. This is the first report showing that the addition of a landiolol to milrinone treatment rapidly restored hemodynamic variables following the optimization of HR by titration of landiolol in ADHF patients with rapid AF. There are several putative mechanisms by which the addition of a low-dose $\beta$-blocker to milrinone improves cardiac function. First, slowing the HR improves incomplete LV relaxation and decreases the myocardial oxygen demand [1]. All patients in the present study were ADHF patients with reduced LVEF, thereby indicating the " $\mathrm{X}$ " pressure $(\mathrm{P})$-volume (V) loop with decreased maximum elastance (E-max; Fig. 1c). Upon inducing tachycardia due to rapid AF, the "X" P-V loop shifts to the "Y" P-V loop, with the decreased SV and the elevated LV end-diastolic pressure (Fig. 1c). Tachycardia shortens the diastolic period, there- by leading to impaired LV filling and decreasing SV [9]. In addition, tachycardia increases the diastolic $\mathrm{Ca}^{2+}$ concentration in the cytosol through diastolic $\mathrm{Ca}^{2+}$ leakage through the ryanodine receptor and decreased $\mathrm{Ca}^{2+}$ uptake due to $\mathrm{Ca}^{2+}$-ATPase on the sarcoplasmic reticulum, which leads to worsening of the impaired LV relaxation $[2-5,10]$. This is because the diastolic P-V curve is shifted upward. The early phase of the diastolic P-V curve shows a particularly great shift [9]. This is a characteristic pattern of incomplete LV relaxation on the diastolic P-V curve. In the present study, landiolol slowed HR without inhibiting cardiac function, and HR optimization by landiolol in combination with milrinone restores " $Y$ " to "X." If landiolol slowed HR while inhibiting cardiac function, the LV end-diastolic pressure would be increased and SVI would be decreased.

Second, slowing the HR improves the contractile property on the force-frequency relationship curve in $\mathrm{ADHF}$ with rapid $\mathrm{AF}$ [11]. It has also been reported that the force-frequency relationship curve decreases at higher HRs in failing hearts, suggesting that there may be a detrimental effect on contractility at higher HRs [11]. Therefore, the addition of low-dose landiolol, which prevents myocardial damage, intracellular $\mathrm{Ca}^{2+}$ overload, and deterioration in hemodynamics due to tachycardia, may be a cardioprotective therapy in patients with ADHF.

Third, low-dose landiolol ameliorates intracellular $\mathrm{Ca}^{2+}$ handling abnormality in HF [4], irrespective of HR. Recently, we reported that: (i) landiolol inhibits $\mathrm{Ca}^{2+}$ leakage from failing RyR2 even at a low dose that did not suppress cardiomyocyte function, and (ii) milrinone treatment enhances $\mathrm{Ca}^{2+}$ leakage from failing RyR2, while adding low-dose landiolol to milrinone suppresses this milrinone-induced $\mathrm{Ca}^{2+}$ leakage, leading to greater improvement in cardiomyocyte function [4]. Additionally, 
Fig. 1. Hemodynamic profiles of ADHF patients with reduced LVEF and rapid AF. a Changes in each hemodynamic parameter at the time of admission (baseline), premilrinone, post-milrinone (no landiolol), and during milrinone plus various doses of landiolol $\left(0-6 \mu \mathrm{g} / \mathrm{kg}^{-1} / \mathrm{min}^{-1}\right)$. All patients were first treated with milrinone, diuretics, and vasodilators, and then various doses of landiolol were added in a step-wise manner. b Changes of hemodynamic parameters between milrinone monotherapy and milrinone with $1.5 \mu \mathrm{g} / \mathrm{kg}^{-1} / \mathrm{min}^{-1}$ of landiolol. Bars indicate the mean \pm standard error. ${ }^{*} p<0.01$. The Wilcoxon signed-rank test was used to compare hemodynamic changes between 0 and $1.5 \mu \mathrm{g} / \mathrm{kg}^{-1} / \mathrm{min}^{-1}$ of landiolol. c Underlying mechanism for optimal reduction of $\mathrm{HR}$ and restoration of LV incomplete relaxation. The LV pressure-volume loop (" $\mathrm{X}$ ") is shifted to " $\mathrm{Y}$ " when rapid $\mathrm{AF}$ is complicated in patients with heart failure and reduced E-max, who are treated with milrinone. "Y" is characterized by a decreased stroke volume and increased diastolic pressure, which is attributable to incomplete LV relaxation. HR optimization by landiolol in combination with milrinone restores " $Y$ " to "X." Data are given as the mean \pm standard error. $* p<0.01$ versus milrinone therapy (at $0 \mu \mathrm{g}$ / $\mathrm{kg}^{-1} / \mathrm{min}^{-1}$ landiolol). Base, baseline; PreMil, pre-milrinone; $\mathrm{HR}$, heart rate; $\mathrm{BPs}$, systolic arterial pressure; CI, cardiac index; PCWP, pulmonary capillary wedge pressure; SVR, systemic vascular resistance; mRAP, mean right atrial pressure; SVI, stroke volume index; $\mathrm{SVO}_{2}$, oxygen saturation of mixed venous blood; LV, left ventricle; E-max (maximum elastance), the slope of the end-systolic pressure-volume relation, representing an index of LV contractility; SV, stroke volume.
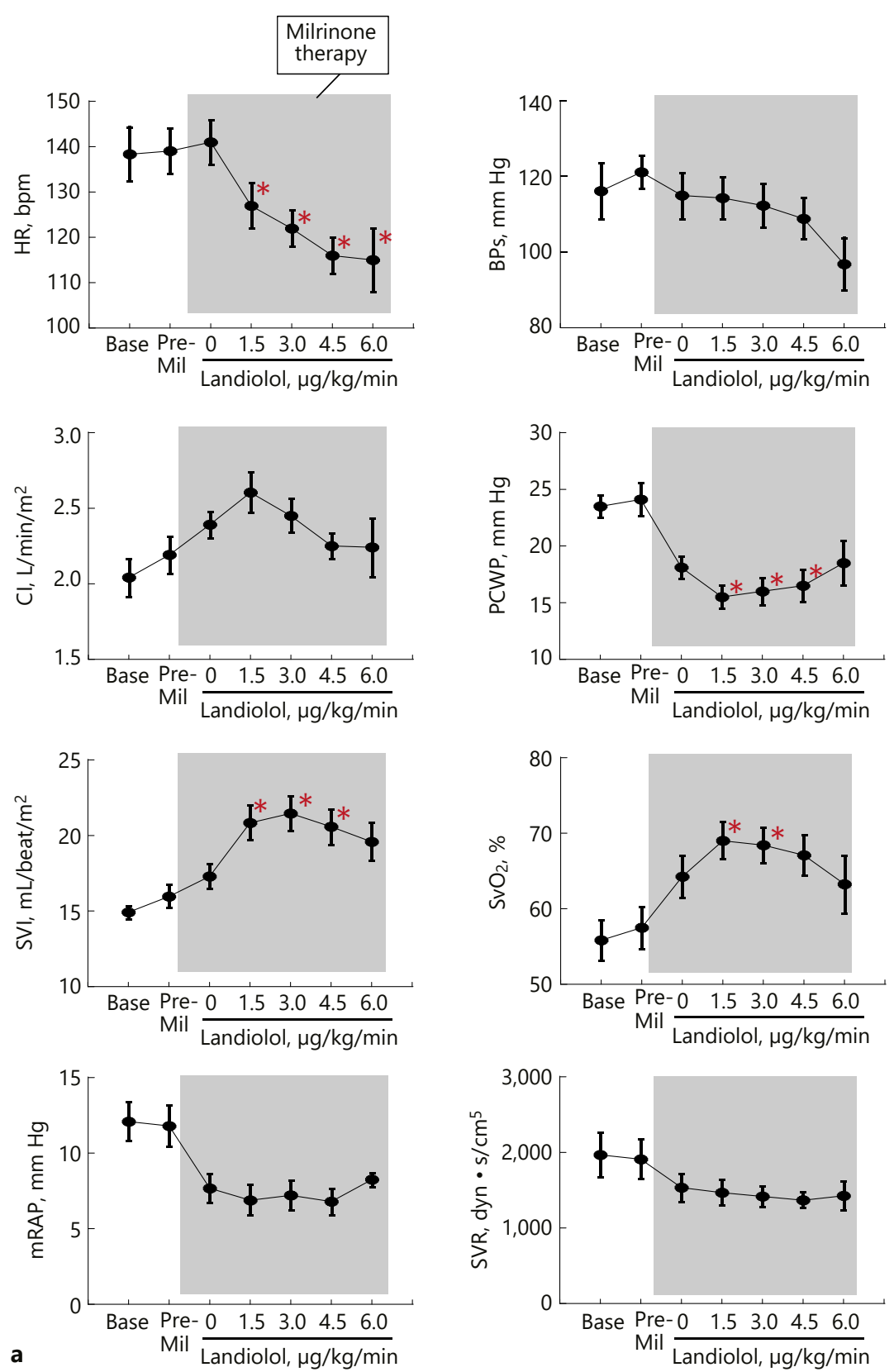

(Figure continued on next page.) inotropes, such as milrinone or catecholamines, enhance diastolic $\mathrm{Ca}^{2+}$ leakage through RyR2, thereby resulting in lethal arrhythmias, such as ventricular tachycardia, due to delayed after depolarization $[4,12]$. Therefore, lowdose landiolol in combination with milrinone may possess a significant advantage in preventing lethal arrhythmias in patients with acute HF.

$\beta$-Blocker and Milrinone in Acute Heart Failure
ADHF patients with normal BP and CI should not easily be given inotropes. Inotropes do not improve the short- and long-term prognosis in ADHF, and can cause adverse effects such as lethal arrhythmia [13]. The 9 patients enrolled in the present study had a clinical profile of "cold and wet" according to the Nohria-Stevenson classification. In addition, as shown in Table 1, 7 patients 

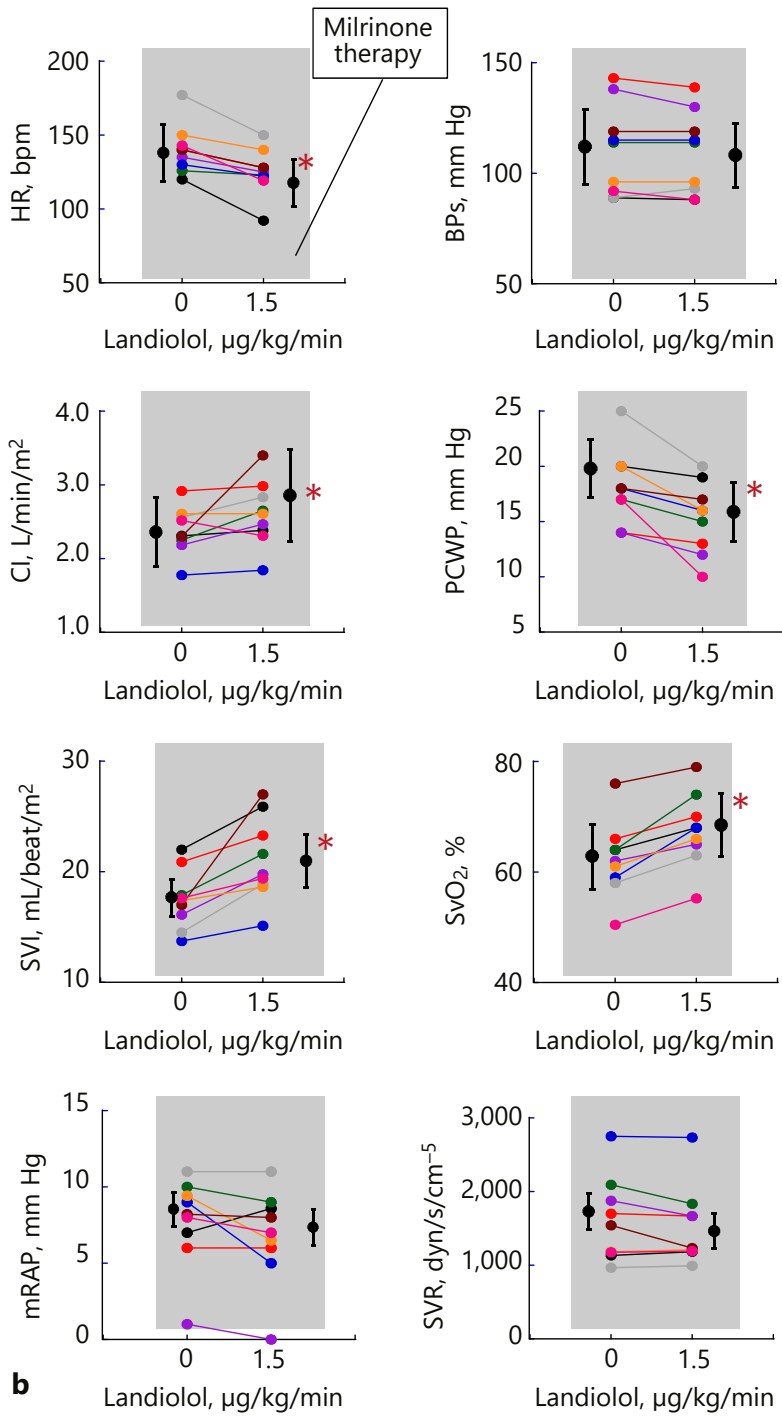

1

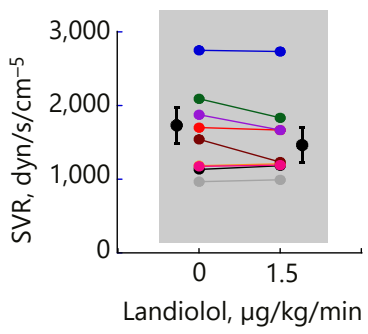

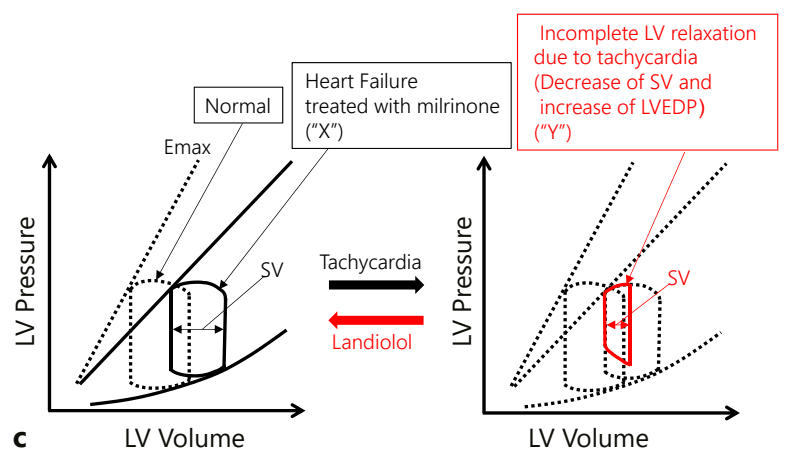

(case No. 1, 2, 3, 4, 5, 7, and 9) had Forrester subset IV baseline hemodynamics and 2 (case No. 6 and 8 ) had Forrester subset II that was equivalent to Forrester subset IV because of a very low SVI $\left(14.7 \mathrm{~mL} / \mathrm{m}^{2}\right.$ in case 6 and 17.3 $\mathrm{mL} / \mathrm{m}^{2}$ in case 8 ), even if their CI was more than $2.2 \mathrm{~L} /$ $\mathrm{min} / \mathrm{m}^{2}$. For peripheral circulatory failure, milrinone was co-administered, and landiolol titration was carried out because of the lack of decrease in HR. Taking advantage of this ultra-short-acting $\beta 1$-blocker, we clarified the beneficial effect of a low dose of landiolol, which has potent negative chronotropism but no negative inotropism, on hemodynamic changes (increased SVI and decreased PCWP).
Decongestion by diuretics is important for the treatment of ADHF with volume overload (high RAP), and successful decongestion generally improves hemodynamics (RAP, PCWP), and subsequently lowers the HR. However, in the present study, although diuretics, vasodilators, and then milrinone were added over more than $4 \mathrm{~h}$, the HR did not decrease at all during these treatments. Although the duration of the initial treatment prior to landiolol administration might have been insufficient, RAP and PCWP prior to landiolol significantly decreased compared to the baseline (change of PCWP -5.4 $\pm 4.2 \mathrm{~mm} \mathrm{Hg}$; change of RAP $-4.4 \pm 5.0 \mathrm{~mm} \mathrm{Hg}$, respectively; Table 2). Based on these results, the very low stroke 
volume due to severe LV dysfunction may explain why the HR did not decrease.

Regarding whether milrinone itself increased the HRs (adverse effect), there were no differences observed before and after administration (pre-milrinone 138.4 \pm 17.9 bpm vs. post-milrinone [no landiolol] $140.1 \pm 16.5 \mathrm{bpm}$, $p=n s)$, as shown in Figure 1a. In addition, the doses of infused milrinone $\left(0.25 \pm 0.10 \mu \mathrm{g} / \mathrm{kg}^{-1} / \mathrm{min}^{-1}\right)$ were low in all cases. Based on these findings, we believe that the effect of milrinone on HR is not significant, while low output syndrome is central to the increased HR.

Finally, on the basis of evidence from trials [14], digitalis and amiodarone are recommended for acute HR reduction in ADHF patients with rapid AF, while intravenous $\beta$-blockers and non-dihydropyridine calciumchannel antagonists are not recommended because of their negative inotropic effect. However, low-dose landiolol, which has strong negative chronotropism but no negative inotropism, was shown to be useful and safe for HR control $[4,6-8,15]$. Therefore, in patients with severe $\mathrm{ADHF}$ and rapid AF (HR $\geq 120 \mathrm{bpm})$, low-dose landiolol may be an alternative first-line therapy to intravenous digitalis and amiodarone, or an additional second-line therapy in ADHF patients with rapid AF refractory to intravenous digitalis or amiodarone administration. In addition, low-dose short-acting $\beta$-blockers may also be useful as a bridge to starting oral $\beta$-blockers in hemodynamically stable, hospitalized HF patients.

\section{Limitations}

There are several limitations to the present study. First, further clinical studies will help to conclusively demonstrate the effectiveness and safety of low-dose landiolol and the described treatment strategy since the patient population in the present study was small. In the present study, taking advantage of this ultra-short-acting $\beta 1$ blocker, we diligently and precisely examined the effect of a low dose of landiolol on hemodynamic changes by quick titration. Second, there are no parallel control data of patients that received no therapy or active controls. Third, although we proposed that HR reduction by the addition of a low-dose landiolol to milrinone therapy has a critical role in improving LV relaxation impairment, as suggested by the shifts in the LV P-V loops in the present study, we could not calculate E-max. However, upon the addition of a low dose of landiolol to milrinone, SVI significantly increased and PCWP significantly decreased despite HR reduction. This mechanism might be attributable to the multiple effects of $\beta$-blockers (e.g., correction of intracellular $\mathrm{Ca}^{2+}$ handling abnormality, improvements in LV relaxation and myocardial $\mathrm{O}_{2}$ consumption, as well as the force-frequency relationship of HR reduction).

\section{Conclusions}

The addition of landiolol at doses of $<3.0 \mu \mathrm{g} / \mathrm{kg} / \mathrm{min}$ to milrinone improved cardiac function in ADHF with rapid AF by selectively reducing HR.

\section{Acknowledgments}

This work was funded by grants-in-aid for scientific research from the Ministry of Education in Japan (Grant No. 18K08039 to S.K.) as well as grants from the Takeda Science Foundation in Japan to S.K. We thank the patients and their families for their participation in this study.

\section{Disclosure Statement}

The authors declare no competing financial interests.

\section{Statement of Ethics}

The Institutional Review Board of Yamaguchi University Hospital approved this protocol (No. H19-87), and all patients provided written informed consent.

\section{References}

$\beta$-Blocker and Milrinone in Acute Heart Failure
1 Andersson B, Lomsky M, Waagstein F. The link between acute haemodynamic adrenergic $\beta$-blockade and long-term effects in patients with heart failure. A study on diastolic function, heart rate and myocardial metabolism following intravenous metoprolol. Eur Heart J. 1993 Oct;14(10):1375-85.

2 Baartscheer A, Schumacher CA, Belterman CN, Coronel R, Fiolet JW. SR calcium han- dling and calcium after-transients in a rabbit model of heart failure. Cardiovasc Res. 2003 Apr;58(1):99-108.

3 Doi M, Yano M, Kobayashi S, Kohno M, Tokuhisa T, Okuda S, et al. Propranolol prevents the development of heart failure by restoring FKBP12.6-mediated stabilization of ryanodine receptor. Circulation. 2002 Mar; 105(11):1374-9. 
4 Kobayashi S, Susa T, Ishiguchi H, Myoren T, Murakami W, Kato T, et al. A low-dose $\beta 1$ blocker in combination with milrinone improves intracellular $\mathrm{Ca} 2+$ handling in failing cardiomyocytes by inhibition of milrinoneinduced diastolic $\mathrm{Ca} 2+$ leakage from the sarcoplasmic reticulum. PLoS One. 2015 Jan; 10(1):e0114314.

5 Gopinathannair R, Etheridge SP, Marchlinski FE, Spinale FG, Lakkireddy D, Olshansky B. Arrhythmia-Induced Cardiomyopathies: Mechanisms, Recognition, and Management. J Am Coll Cardiol. 2015 Oct;66(15):1714-28.

6 Ikeshita K, Nishikawa K, Toriyama S, Yamashita T, Tani Y, Yamada T, et al. Landiolol has a less potent negative inotropic effect than esmolol in isolated rabbit hearts. J Anesth. 2008;22(4):361-6.

7 Kobayashi S, Susa T, Tanaka T, Murakami W, Fukuta S, Okuda S, et al. Low-dose $\beta$-blocker in combination with milrinone safely improves cardiac function and eliminates pulsus alternans in patients with acute decompensated heart failure. Circ J. 2012;76(7):164653.
8 Kobayashi S, Murakami W, Myoren T, Tateishi H, Okuda S, Doi M, et al. A low-dose $\beta 1$ blocker effectively and safely slows the heart rate in patients with acute decompensated heart failure and rapid atrial fibrillation. Cardiology. 2014;127(2):105-13.

9 Zipes DP, Libby P, Bonow RO, et al. Braunwald's heart disease: a textbook of cardiovascular medicine. 7th ed. Philadelphia: WB Saunsers; 2004. pp. 457-538.

10 Selby DE, Palmer BM, LeWinter MM, Meyer M. Tachycardia-induced diastolic dysfunction and resting tone in myocardium from patients with a normal ejection fraction. J Am Coll Cardiol. 2011 Jul;58(2):147-54.

11 Mulieri LA, Hasenfuss G, Leavitt B, Allen PD, Alpert NR. Altered myocardial force-frequency relation in human heart failure. Circulation. 1992 May;85(5):1743-50.

12 Anderson ME, Hodgson-Zingman DM. Ventricular tachycardia in patients with heart failure. In: Zipes DP, Jalife J, Sauders WB, editors. Cardiac electrophysiology: from cell to bedside. 5th ed. Philadelphia: Saunders; 2009. pp. 707-16.
13 Mortara A, Oliva F, Metra M, Carbonieri E, Di Lenarda A, Gorini M, et al.; IN-HF Outcome Investigators. Treatment with inotropes and related prognosis in acute heart failure: contemporary data from the Italian Network on Heart Failure (IN-HF) Outcome registry. J Heart Lung Transplant. 2014 Oct; 33(10):1056-65.

14 Kirchhof P, Benussi S, Kotecha D, Ahlsson A, Atar D, Casadei B, et al.; ESC Scientific Document Group. 2016 ESC Guidelines for the management of atrial fibrillation developed in collaboration with EACTS. Eur Heart J. 2016 Oct;37(38):2893-962.

15 Nagai R, Kinugawa $\mathrm{K}$, Inoue $\mathrm{H}$, Atarashi $\mathrm{H}$, Seino Y, Yamashita T, et al.; J-Land Investigators. Urgent management of rapid heart rate in patients with atrial fibrillation/flutter and left ventricular dysfunction: comparison of the ultra-short-acting $\beta 1$-selective blocker landiolol with digoxin (J-Land Study). Circ J. 2013;77(4):908-16. 